\title{
Editorial
}

\section{A total society of knowledge}

The major Lisbon goal is to give Europe back the primacy as a society of knowledge. 'Giving back' is a more appropriate term than 'giving', as Europe long held that primacy in the past, and virtually as a monopoliser from the $17^{\text {th }}$ century throughout the $19^{\text {th }}$. Then, Europe shared it with North America for a long portion of the $20^{\text {th }}$ century.

Today, Europe does not hold that supremacy any longer. Figures tell it. Asia is once again the continent where investments in scientific research and technological development (R\&D) are the highest. Whereas - for the first time in ages - Europe is investing less (2007 R\&D investments accounted for 1.8\% of GDP) than the world average (2007 R\&D investments accounted for $2.1 \%$ of GDP). So, Europe is struggling to keep up with «the others», in terms of absolute investments and investment intensity.

Hence the need to make up lost ground and supremacy.

Obviously, higher investments are not enough. Spending for R\&D is a necessary factor, yet not sufficient, to build a knowledge-based economy. It is even truer if - as customary in Europe - while building this economy a great focus is to be placed on justice and social integration. In Lisbon, Europe said it does not want to be only a leader of knowledge economy. Europe is much more ambitious than that: it wants to be a leader - or rather a pioneer - in building a «democratic society based on knowledge». Europe, in other terms, is facing the issue of the social and ecologic sustainability of a knowledge-based economy.

What should be done to achieve such a visionary goal? Certainly, what is needed is to enhance the productive specialisation in the field of high technologies and of high-knowledge-intensity commodities production: therefore, to increase the demand for scientific research in the European productive system. Yet to implement a knowledge-based economy, especially in the framework of a new welfare, one needs to put factories and universities aside, to overcome a simple transfer of knowledge from where it is produced (universities, research centres) to where it is used for the production of goods (businesses). What is needed is to create an entire «environment suitable for innovation» and, consequently, to involve the entire society. In other words, what is needed is a scientific culture widespread all through the entire society and a real democratic participation to harness the transition process from an industrial economy to a knowledge-based economy.

In other terms, what is strongly needed is a society where citizens are players within innovation processes and not only mere consumers. What is needed is not an environment with a higher presence and (acceptance) of science. What is needed is an environment where science and society are tightly and mutually interwoven.

Under this perspective, it has possibly been a mistake to call Science in Society the initiatives within the Seventh Framework Programme (FP7) whose «aim is to stimulate the harmonious integration of scientific and technological endeavour and associated research policies into European society with a view to building an effective and democratic European knowledge-based society». It might suggest a series of initiatives that only deal with a better efficiency in the «know-how transfer» and in a better social acceptability of technical and scientific innovation through a wisely modulated agenda-setting. No matter how refined, such an "instrumental policy" would have some limitations. Both in creating a stable knowledge-based economy and, most of all, in creating a democratic and sustainable society of knowledge.

Creating an environment suitable for innovation means not only to innervate society with a scientific culture, but also to innervate scientific activity with social requests. Hence, the relations between Science and Society cannot be anything but a bilateral communication process through a richer and richer set of channels. Because it should involve scientific communities and all the citizens in building an articulated yet widespread scientific culture (which is an exercise of critical attitude in the first place). And because it should involve scientific communities and all the citizens in identifying social and ecological sustainability objectives and in the transparency of scientific research and technological development processes. 
If we want it to be democratic, we should build a «total society of knowledge». Where everybody can in principle - not only access and use knowledge, but also produce, develop and drive it.

Translated by Massimo Caregnato

Pietro Greco 